\title{
Discurso, memória e identidades em Uma carta pela mudança do Maranhão: análise de uma peça publicitária da campanha eleitoral de Flávio Dino (MA-2014)
}

\author{
Discourse, memory and identities in Uma carta pela mudança do Maranhão: analysis \\ of an advertisement piece of Flávio Dino campaign (MA-2014) \\ Mônica da Silva CRUZ* \\ Universidade Federal do Maranhão (UFMA) \\ Thayane Soares da SILVA** \\ Universidade Federal do Maranhão (UFMA)
}

\begin{abstract}
RESUMO: Neste artigo apresentamos uma investigação sobre a produção de sentidos na campanha político-eleitoral de Flávio Dino (PCdoB), do ano de 2014, mais especificamente analisamos uma peça publicitária intitulada Carta aos Maranhenses. São mobilizados princípios conceituais da Análise do Discurso de linha francesa, algumas contribuições de Michel Foucault para entendimento das formas de produção e circulação dos discursos e estudos sobre discurso político, memória e mídias (COURTINE, 2011; PÊCHEUX, 1999; GREGOLIN 2007; 2008); as identidades são discutidas da perspectiva dos Estudos Culturais (BAUMAN, 2005; HALL, 2006). Esta análise é um recorte de uma pesquisa de mestrado que está sendo desenvolvida, no âmbito das discussões do Grupo de Pesquisa em Linguagem e Discurso do Maranhão (GPELD - MA).
\end{abstract}

PALAVRAS-CHAVE: Discurso Político. Flávio Dino. Análise do Discurso.

ABSTRACT: In this paper we presente an investigation about the production of meanings in Flávio Dino's (PCdoB) electoral campaign, of 2014, more specifically we analyzed an advertising piece entitled Uma carta pela mudança do Maranhão. We mobilized conceptual principles of french Discourse Analysis, some contributions by Michel Foucault for understanding the forms of discourse production and circulation, and studies on political discourse, memory, and media (COURTINE, 2011; PECHÊUX, 1999; GREGOLIN 2007;); The identities were discussed from the perspective of Cultural Studies (BAUMAN, 2005; HALL, 2006). This analysis is an outline of a master 's research that is being developed in the context of Grupo de Pesquisa em Linguagem e Discurso do Maranhão (GPELD - MA) discussions

KEYWORDS: Political discourse. Flávio Dino. Discourse analysis.

\section{Introdução}

Em uma sociedade midiática na qual a política se manifesta como espaço de embates discursivos, apresentamos neste artigo um recorte de uma pesquisa de mestrado que busca como objetivo geral avaliar memórias produzidas para o comunismo em um acontecimento discursivo: a participação de um candidato do Partido Comunista do Brasil nas eleições estaduais no Maranhão de 2014. Nele investigamos,

\footnotetext{
* Doutora em Linguística e Língua Portuguesa pela Universidade Estadual Paulista Julio de Mesquita Filho (Unesp/Araraquara) e Professora do Programa de Pós-Graduação em Letras (PGLetras - UFMA).

${ }^{* *}$ Mestra em Letras pela Universidade Federal do Maranhão (PGLetras - UFMA).
} 
especificamente, efeitos de sentido que emergiram na mídia, a partir da associação do então candidato Flávio Dino à memória do comunismo, durante as eleições de 2014.

No caminho percorrido deste trabalho até o momento, alguns questionamentos balizaram nosso trajeto de investigação sobre os efeitos de sentido que emergiram na mídia a partir da associação do candidato Flávio Dino (PCdoB) à memória do comunismo. Um desses questionamentos nos guiou ao objetivo de identificar as condições de possibilidade e as formas de circulação dos discursos nesse processo de discursivização das identidades do candidato. Assim, propomos neste artigo uma análise da produção de sentidos sobre as identidades do então candidato Flávio Dino, verificando como mecanismos discursivos são mobilizados na construção das identidades do candidato em uma peça publicitária de sua campanha eleitoral 2014, intitulada Carta aos Maranhenses.

Utilizamos, para tanto, princípios conceituais da Análise do Discurso de linha francesa e de estudos sobre discurso político, memória e mídias (COURTINE, 2011; PECHÊUX, 1999; GREGOLIN 2007; 2008); e as identidades são discutidas da perspectiva dos Estudos Culturais (HALL, 2006; BAUMAN, 2005).

Na próxima seção tratamos brevemente da constituição do campo da $\mathrm{AD}$ e sobre as categorias teórico-analíticas utilizadas na construção de nossa análise.

\section{Análise do discurso, transformações do discurso político e identidades}

A AD se construiu inicialmente tendo como base a confluência de três diferentes e complementares áreas do saber: uma teoria da história, mais especificamente do materialismo histórico, centrada nas releituras que Althusser fez das obras de Marx, para explicar as trans(formações) sociais, já que é na/pela história que buscamos observar as condições de produção dos discursos; uma teoria da psicanálise, advinda das releituras que Lacan fez das teorias freudianas, para explicar a noção de sujeito e como este, em sua relação com o simbólico, é afetado pelo inconsciente e pela ideologia; e uma teoria da linguística, partindo das releituras de Saussure, para explicar a linguagem e os processos de enunciação, já que a AD trabalha também com elementos linguísticos. Esse caráter transdisciplinar da $\mathrm{AD}$ é explicado pela própria natureza complexa dos discursos. 
Foucault se aproxima dos estudos do discurso à medida que se interessa não pela lingua(gem) em si, mas por suas possibilidades, por aquilo que é permitido produzir em sua utilização, ou seja, o interesse dele é pelo discurso, pois é através do discurso que se dão as escolhas e as combinações dos próprios signos linguísticos. A concepção foucaultiana de discurso refere-se a um "número limitado de enunciados para os quais podemos definir um conjunto de condições de existência" (FOUCAULT, 2008, p.132133), ou seja, o discurso é formado por um conjunto de enunciados (suas unidades mínimas) pertencentes a uma mesma formação discursiva (FD). Ainda segundo a proposta foucaultiana, o discurso é o que autoriza/limita a série de desempenhos possíveis da língua, e é aí que se inscreve o foco de sua pesquisa discursiva, voltada para entender algo anterior até mesmo à materialização do discurso, que é questão de seu acontecimento, para entender a construção dos enunciados e as condições que permitem sua emergência singular.

Para se trabalhar a análise da produção e circulação do discurso político, de modo a preservar a articulação entre a materialidade do discurso e sua historicidade, neste estudo, cuja ancoragem é a Análise do Discurso de base foucaultiana, tomamos como conceitos nucleares noções como "Enunciado" e "Formação Discursiva".

O conceito de formação discursiva (FOUCAULT, 2008) refere-se então ao que pode ser dito em uma época em um espaço social determinado, ao que tem lugar e realização através de condições de produção específicas, historicamente definidas. Trata-se da possibilidade de explicitar como cada enunciado tem o seu lugar e sua regra de aparição, e como as estratégias que o engendram derivam de um mesmo jogo de relações, como um dizer tem espaço em um lugar e em uma época específica.

Os enunciados, então, como irrupções históricas dos acontecimentos discursivos em suas singularidades que não se esgotam nem na língua, nem em seu sentido (FOUCAULT, 2008), estarão sempre filiados às relações históricas que o perpassam e a um campo de memória, o que permitirá a existência de ligações, transferências e identificações.

A partir do conceito foucaultiano de discurso anteriormente citado, podemos entender ainda o enunciado como unidade mínima dos acontecimentos discursivos, que emerge sempre em conexão com outros enunciados e pertencem a uma mesma 
formação discursiva. O acontecimento é, portanto, a emergência de enunciados interconectados que produzem efeitos de sentido e constituem as Formações Discursivas. Todo enunciado dialoga com outros enunciados, posto que este também não é um elemento autônomo. Ele se encontra inscrito em uma rede, relacionando-se com enunciados que o precedem e gerando a irrupção de novos enunciados, que irão aparecer, nas vozes de vários enunciadores, sendo retomados, reformulados, desdobrados.

Segundo Pêcheux (1999), a memória, no âmbito dos estudos discursivos, não pode ser considerada como uma proposta de uma memória psicológica individual, mas sim de uma memória discursiva, que é social, inserida em práticas e efeito da presença do interdiscurso no acontecimento discursivo. E é preciso considerar que todo dizer carrega uma memória, um já-lá, que determina como os discursos devem circular.

Essa noção de memória discursiva, tal como cunhada por Jean-Jaques Courtine, em 1981, aparece em seus já citados estudos do discurso político, e foi desenvolvida a partir das leituras que este autor fez das reflexões de Foucault sobre o enunciado. Por isso, este conceito está intimamente ligado ao de "domínio de memória" desenvolvido por Foucault. Courtine referência a obra foucaultiana como sua fonte para utilização dos termos "domínio de memória", "domínio associado" e "domínio de atualidade", porém ressalta: "demos a eles aqui um valor sensivelmente diferente". (COURTINE, 2014, p. 111)

Uma das grandes constatações de Courtine (2011) acerca das transformações do discurso político é sobre a linguagem tradicional do discurso político, chamada de língua de madeira, estar se aproximando cada vez mais da língua de vento, termo usado pelo autor para designar a linguagem publicitária.

O autor compreende que o discurso político buscou utilizar as línguas de vento que são caracterizadas por sua volatilidade e instabilidade e, por consequência, acabam por torná-las mais atraentes. Para Courtine, Pêcheux também se preocupou em pensar sobre esta dimensão do discurso político, pois para este último a ciência tem fundamentos no político.

Todas essas transformações operadas nos discursos políticos se devem a este importante aspecto da Pós-modernidade que foi o desenvolvimento e expansão da mídia 
(impressa e eletrônica), dos veículos de comunicação em massa (TV, celular, internet) e das instituições modernas, que operaram mudanças fundamentais em nossa sociedade para que a comunicação política fizesse o caminho do palanque até a TV e outras mídias. Então não é mais somente nos panfletos ou jornais, mas também no Horário Eleitoral Gratuito da televisão e nas redes sociais que podemos agora observar $A s$ metamorfoses do homo politicus, que agora têm a oportunidade de "editar" suas identidades em seus "perfis" divulgados nas redes e através das imagens, notícias e propostas que divulgam em seus próprios canais de comunicação. Assim, através de práticas diversas, em diferentes “telas”, produzem-se subjetividades.

Sob perspectiva histórica e discursiva, entendemos neste estudo a constituição das identidades, compreendidas como elemento sempre constituído em processo. Segundo Hall (2006, p.38),

\footnotetext{
a identidade é realmente algo formado, ao longo do tempo, através de processos inconscientes, e não algo inato, existente na consciência no momento do nascimento. Existe sempre algo 'imaginário' ou fantasiado sobre sua unidade. Ela permanece sempre incompleta, está sempre 'em processo', sempre 'sendo formada'.
}

Esse objeto constitui-se em um elo entre a $\mathrm{AD}$ e os Estudos Culturais, como discutido por Gregolin (2008), em Identidade: objeto ainda não identificado?, texto no qual propõe a interlocução entre os dois campos. Foucault também se interessou em seus estudos pelas formas de subjetivação, e adota a posição de que os discursos constroem os objetos de que falam. Então, para a Análise do Discurso, as identidades, como objetos de estudos, são entendidas como construções históricas que se dão dentro de práticas discursivas. A mídia é, desse modo, entendida aqui como prática discursiva (GREGOLIN, 2007), ou seja, o principal "lugar" no qual os discursos - efeitos de sentidos instaurados por sujeitos sócio-históricos - circulam nas mais diferentes materialidades (verbais e não verbais). Segundo Foucault (2008), prática discursiva não é o mesmo que uma simples expressão/formulação de ideias ou desejos. Também não podemos dizer que se trata de uma atividade racional ou uma competência. Situar-se em uma prática discursiva é "falar"/enunciar segundo determinadas regras, e fazer manifestarem-se as relações que ocorrem dentro de um discurso. A mídia é, desse modo, grande responsável pela intensa produção identitária atual. Podemos entender a mídia, por exemplo, como uma prática discursiva que enuncia e produz diversas 
identidades, não de qualquer maneira, mas segundo determinadas regras, fazendo manifestarem-se as relações que se dão dentro de um discurso.

Tendo exposto nesta seção o lugar teórico-metodológico a partir do qual construímos nossa investigação, bem como as categorias teórico-analíticas utilizadas nas análises de nossos corpora, passaremos agora a buscar as condições de produção e emergência dos discursos que são analisados neste artigo.

\section{2. "O candidato comunista" no Maranhão}

Apresentamos nesta seção uma breve reflexão sobre as condições sóciohistóricas da emergência desse discurso identitário e da inserção de Flávio Dino na cena política maranhense, que tem seu ponto alto em 2014. Este ano foi o último ano do governo de Roseana Sarney, que havia saído vitoriosa nas eleições estaduais de 2010, em um mandato iniciado logo após ter voltado ao cargo em 2009, por decisão do Tribunal Superior Eleitoral, que destituiu do poder o então governador Jackson Lago por denúncias de irregularidades durante as eleições de 2006. Outro acontecimento importante no cenário político maranhense de 2014, na esfera estadual, foi o embate dos candidatos que figuravam à frente da disputa: Edison Lobão Filho (PMDB), apoiado pela então governadora, e Flávio Dino (PCdoB).

Flávio Dino já havia sido candidato a governador do estado em 2010, quando perdeu as eleições em primeiro turno para Roseana Sarney; já em 2014, o candidato angariou novas alianças com partidos de oposição e ex-aliados ao governo do estado, o que indicava uma maior expectativa de vitória. Durante o período eleitoral as propagandas políticas, notícias e entrevistas com os candidatos colocaram em discussão alguns temas, como a segurança pública; mudança, em razão da luta que os candidatos de oposição assumiam como apelo para o fim da chamada "oligarquia" do Maranhão; e aquele que nos chamou atenção para a investigação que propomos: o comunismo. Este veio a ser um tema bastante produtivo por razão da presença de um candidato do Partido Comunista do Brasil no pleito.

Formado desde 1991, pela Universidade Federal do Maranhão, em Direito, Flávio Dino voltou à mesma universidade, em 1993, dessa vez como professor, após ser aprovado em concurso público. Mais tarde fora aprovado também para exercer o cargo 
de juiz federal, o qual exerceu por 15 anos no Maranhão, chegando a ser presidente da Associação Nacional dos Juízes Federais e secretário geral do Conselho Nacional de Justiça, o que lhe rendeu destaque na mídia em nível nacional. O então ex-juiz federal, que havia sido filiado ao PT de 1987 a 1994, filiou-se ao partido PCdoB em 2006, com vistas a concorrer às eleições a deputado federal pelo Maranhão, cargo para o qual foi eleito no mesmo ano. Este foi o momento em que o candidato ingressou na vida política.

Em 2008 deu início a sua campanha nas eleições municipais de São Luís, em coligação entre PCdoB e PT. Naquele momento, alguns dos adversários de Flávio Dino que mais se destacavam nas pesquisas, como João Castelo, Clodomir Paz e Raimundo Cutrim, valeram-se das "prévias experiências administrativas e de gestão pública (por eleição ou indicação para cargos de confiança) e as acionaram com o propósito de dar consistência e confiabilidade aos seus discursos e propostas." (BORGES, 2008, p.12). Assim, apesar de veicular naquela campanha a autoimagem de um candidato novo, que estava aliado a Lula e preparado pela sua formação acadêmica, conhecimento das leis e dos caminhos de obtenção de recursos, o candidato foi apresentado pelos oponentes como inexperiente, comunista, sarneysta e inimigo dos mais velhos e das Igrejas (BORGES, 2008). Essa não veio a ser uma disputa vitoriosa para Flávio Dino, mas fora importante para o caminho político do candidato "que passou de $4 \%$ das intenções de voto no início da campanha para 34\% dos votos" (BORGES, 2008, p. 19), disputando o segundo turno com João Castelo.

Sobre essa jornada política percorrida por Flávio Dino de 2006 a 2010 e seu destaque no cenário político da capital Maranhense, Moura (2013, p. 39) comenta:

\footnotetext{
Na eleição de 2006, Flávio Dino foi o quarto candidato mais votado em todo Maranhão. Durante seu mandato foi eleito, pelo site Congresso em Foco, um dos melhores parlamentares do país, por quatro anos consecutivos. A boa avaliação de sua atuação na Câmara Federal o habilitou a disputar a prefeitura de São Luís, em 2008, perdendo a disputa no segundo turno para o político João Castelo. Em 2010, na reta final da campanha para o governo do Estado, obteve um bom desempenho nas intenções de voto, alcançando o segundo lugar na disputa eleitoral.
}

Apesar de já ter tido destaque nacional por outros papéis políticos, como os de deputado federal e ex-presidente da Embratur, Flávio Dino apareceu no arquivo político midiático das eleições estaduais de 2014, por diversas vezes através de entrevistas, debates e nas campanhas de seus opositores sendo discursivizado como "o candidato 
comunista" por meio de uma diversidade de questionamentos sobre o posicionamento político-ideológico e religioso do candidato.

Mas quais condições e mecanismos produzem esse efeito de verdade de divergência entre identidades de um sujeito político na pós-modernidade? No intuito de entender essa questão sobre as condições de possibilidade e de produção desses discursos, é preciso lembrar o gênero discursivo no qual se encontram os enunciados analisados, a entrevista jornalística, para compreender o que deve e o que pode ser dito nesse gênero e as instituições que regulam seus dizeres.

\section{Comunismo e identidades em Uma carta pela mudança do Maranhão}

A análise proposta neste artigo trata de uma peça publicitária intitulada Uma carta pela mudança do Maranhão, elaborada pela Coligação Todos Pelo Maranhão (PC do B, PSDB, PP, SD, PROS, PSB, PDT, PTC, PPS), para o horário eleitoral gratuito do candidato Flávio Dino.

O vídeo dessa peça foi produzido tendo como "roteiro" um texto verbal construído aos moldes de um gênero epistolar. Dessa forma conta então com os recursos da materialidade verbal de uma carta, do imagético do vídeo e com o poder de divulgação que a TV e a internet possuem. Em razão desses fatores, para aprofundarmos nossa análise, seguindo os princípios da Semiologia Histórica, verificamos a seguir como foi construída a dimensão verbal da Carta aos Maranhenses, observando ao mesmo tempo a sincronia ao visual.

Os locais de publicação de circulação desses textos foram a TV, a internet e as ruas, por meio de um panfleto, que também foi distribuído pelas casas maranhenses. Abaixo temos a transcrição da Carta aos maranhenses:

\footnotetext{
Meus amigos e minhas amigas, quero falar com vocês sobre a nossa terra. Tenho cruzado nosso estado de ponta a ponta. Vejo uma terra tão linda e tão rica. Mas vejo também que essa riqueza chega para poucos. Vejo tanta água e tanta sede de justiça. Por onde ando, percebo o mesmo desejo em cada olhar: o desejo de mudança. Quero conversar com você sobre o Maranhão do futuro. O lugar em que queremos e podemos viver. Que seja de todos, não importa sua raça ou religião, se você é homem ou mulher. Da capital ou do interior. O Maranhão que sonhamos é honesto, decente, justo. Com educação para todos, água para todos, saúde para todos. Com mais oportunidades. A chance está em nossas mãos. Somos um povo trabalhador, somos fortes, temos coragem e muita fé em Deus. Sem ódio, sem rancor, sem medo. Juntos, a gente vai conseguir um Maranhão de todos. Eu acredito no
} 
Maranhão. Que as riquezas de nossa terra podem levar justiça e prosperidade para todos. Tenho fé que a hora chegou. Vamos juntos pela mudança. Todos juntos pelo Maranhão. Abraços, Flávio Dino.

(Portal Vermelho, 2014. Disponível em: <http://www.vermelho.org.br/noticia/248217-1>. Acesso em: 15/08/2015.)

Figura 1: Carta aos Maranhenses Panfleto

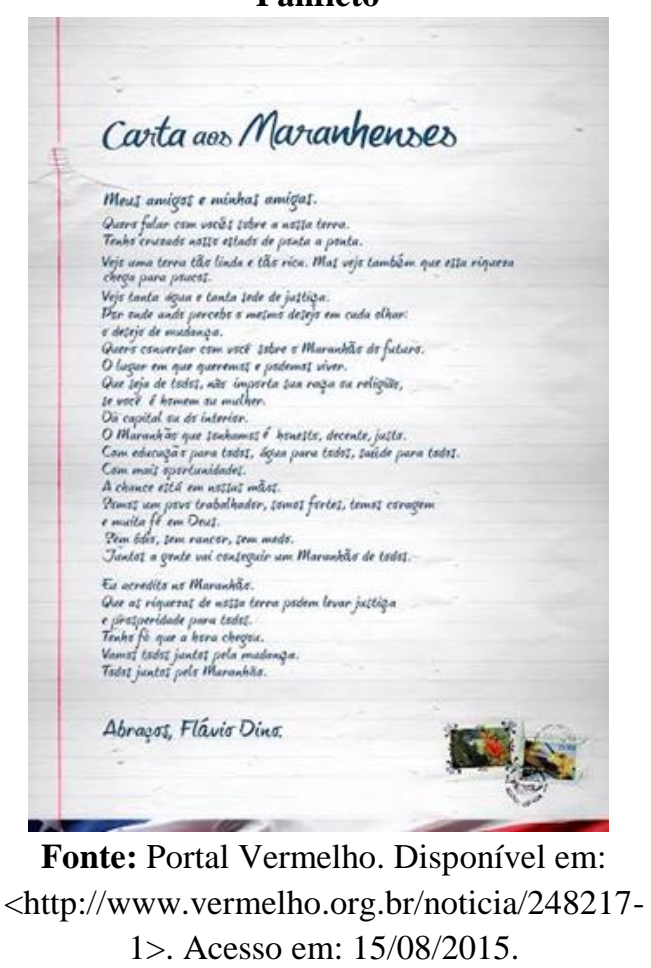

Discorremos agora mais detalhadamente sobre a carta. De acordo com Silva (2002), encontramos neste espaço um fator contextualizador da situação comunicativa, o cabeçalho, que reporta a localização geográfica e a época dessa produção textual.

No vídeo que aqui analisamos, temos uma produção discursiva composta pelo escrito (a carta), o sonoro (sua leitura) e o visual, desse modo, apesar de não expor um cabeçalho em sua dimensão verbal, podemos ver nos primeiros trinta segundos do vídeo toda essa ambientação espacial do gênero carta. $O$ vídeo se inicia com as imagens de um campo aberto, com o sol nascendo ao fundo. Logo depois uma pessoa aparece preparando um café com um tradicional pano de coar café, um carteiro surge andando de bicicleta por uma estrada de terra, um senhor de idade rega uma plantação de hortaliças... e as imagens de homens e mulheres trabalhadores, representando cidadãos maranhenses em suas atividades cotidianas, vão se multiplicando na tela. 
Um deles recebe uma carta das mãos do carteiro mostrado no início do vídeo (Fig. 2), e, na sequência, vários trabalhadores rurais vão recebendo a carta e iniciando suas leituras.

\section{Figura 2: Mãos - Uma carta pela Mudança do Maranhão}

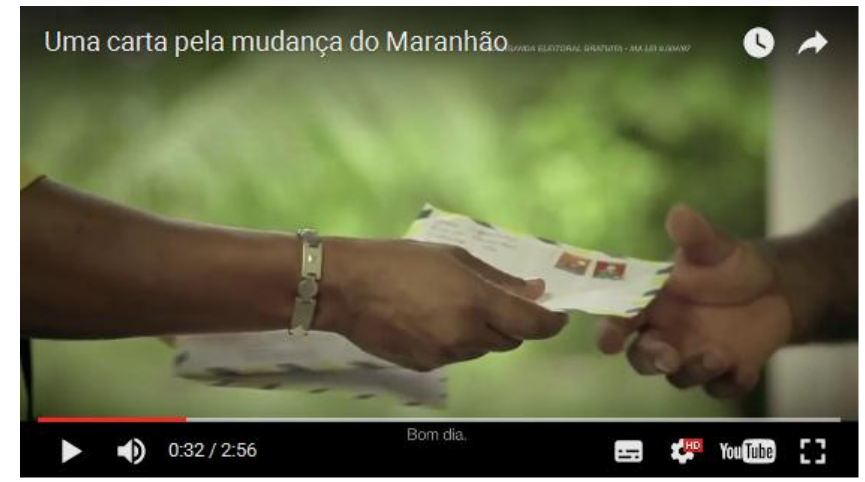

Fonte: Youtube. Disponível em:

$<$ https://www.youtube.com/watch?v=PMP0KomOIhU\&list $=$ PLKWUfqq8cFHn8m6hWc0WYty7B_G_wuxjc $>$. Acesso em: 15/08/2015.

E indo além do vídeo, encontramos outros elementos deste acontecimento discursivo que funcionam como o cabeçalho ausente na carta, comunicando assim sobre a época dessa produção. Pois o vídeo Uma carta pela mudança do Maranhão foi publicizado como primeiro programa de TV da coligação, no dia 21 de agosto de 2014, no horário da noite, e não em outra data qualquer do período estabelecido por lei para a propaganda no horário eleitoral gratuita.

Em Cenografia epistolar e debate público, Maingueneau (2008) pensa a "carta" em sua cenografia de carta privada, quando inserida em um debate público. Este autor entende o discurso como uma cena. Uma cena de enunciação que forma um conjunto com outras três cenas de fala: a cena genérica, a cena englobante e a cenografia.

A cena englobante diz respeito ao tipo de discurso no qual determinado discurso se apresenta. No caso da carta em análise, a cena englobante na qual o leitor deve se posicionar para empreender uma interpretação é o discurso político. Enquanto a cena englobante refere-se à tipologia discursiva, a cena genérica corresponde ao gênero e as duas vão especificar "o espaço estável no interior do qual o enunciado ganha sentido" (MAINGUENEAU, 2008, p. 116). Porém, em cartas como a da campanha de Flávio Dino, podemos dizer, com Maingueneau, que a cenografia se destaca entre as demais cenas de fala. 
A cenografia construída nesta peça publicitária através da carta é, como nas palavras desse autor, "uma encenação pública da relação epistolar privada"; a campanha constrói essa ficção de uma troca epistolar entre candidato e povo maranhense (MAINGUENEAU, 2008, p.121).

Dessa forma, a carta apareceu na mídia como um marco inicial para a construção desse relacionamento entre o candidato e possíveis (e)leitores, nas eleições de 2014.

Como comentado anteriormente, a Carta aos Maranhenses apresenta também elementos do gênero de esfera privada, a "carta pessoal". Talvez isso se deva ao fato de esse texto ser primordialmente uma propaganda política que inicia uma campanha eleitoral de um candidato, sendo guiada, portanto, por uma vontade de construir uma identificação entre os sujeitos. O panfleto foi impresso em um papel estilizado, imitando uma carta real, com letras cursivas que imitam algo manuscrito com uma caneta, em uma folha de caderno, meio amassada, com selos estampados, mas sem nomes de partidos políticos, nem número do candidato, apenas o nome de Flávio Dino na assinatura da carta. Todo esse cuidado com a edição do panfleto, sua distribuição, que foi feita pelas casas e não entregues em qualquer ponto das ruas das cidades maranhenses, além, é claro, de toda a ambientação das leituras que são retratadas no vídeo, em ambientes familiares e cotidianos, vão atenuando os efeitos de impessoalidade e formalidade presentes na "carta aberta" e construindo um efeito de proximidade entre o político e público.

As leituras retratadas acontecem em grupos que aparecem em diferentes espaços: na mesa de jantar de uma família, à beira mar tendo um pescador (Fig. 3) como leitor da carta, que lê como se estivesse em um palanque, imitando os tradicionais pronunciamentos políticos, e numa aldeia indígena, sendo lida por um dos índios na língua de seu povo. Essa inserção da figura indígena na propaganda estabelece um diálogo com o discurso da exaltação da diversidade cultural tanto linguística quanto social dos maranhenses e brasileiros. 
Figura 3: Pescador - Uma carta pela Mudança do Maranhão.

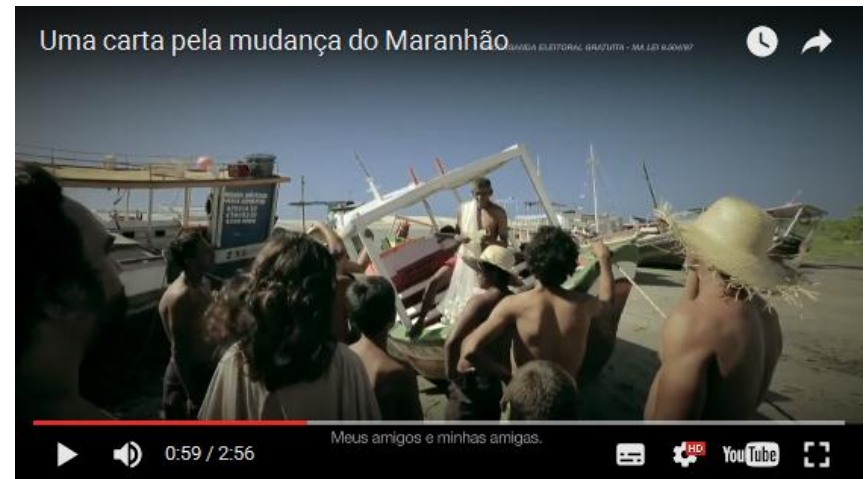

Fonte: Youtube. Disponível em:

<https://www.youtube.com/watch?v=PMP0KomOIhU\&list $=$ PLKWUfqq8cFHn8m6hWc0WYty7B_G_wuxjc >. Acesso em: 15/08/2015. Acesso em: 15/08/2015.

No restante do vídeo a carta vai sendo lida por personagens que representam cidadãos de diversas "classes" e cores: vaqueiro, universitário, artesã, donas de casa, quebradeira de coco, dentista, enfermeira, brincante do bumba-meu-boi e também crianças leem o texto como num jogral e, entre as vozes, por vezes a voz do candidato também pode ser ouvida, sem que sua imagem apareça na tela. No último trecho do texto/vídeo, ouvimos a voz de Flávio Dino, alta e forte, quase aos gritos, como se estivesse num palanque, mas as imagens na tela continuam a mostrar imagens de pontos turísticos do estado e dos cidadãos. Até que ele aparece em um evento como um comício de mãos dadas com seus aliados e eleitores, bastante emocionado (Fig. 04).

Figura 4: Flávio Dino emocionado.

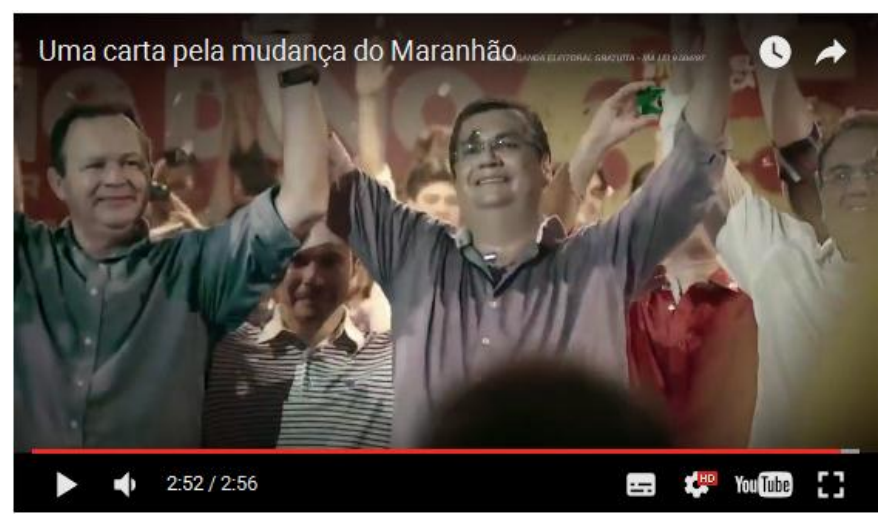

Fonte: Youtube. Disponível em: <https://www.youtube.com/watch?v=PMP0KomOIhU\&list $=$ PLKWUfqq8cFHn8m6hWc0WYty7B_G_wuxjc $>$. Acesso em: $15 / 08 / 2015$. 
Os elementos composicionais da Carta aos Maranhenses nos fazem descrevê-la aqui, como afirmado anteriormente, ao gênero epistolar, ora aproximando-se das práticas das cartas da esfera privada, como uma "carta pessoal", ora tomando elementos daquelas da esfera pública, como uma "carta aberta".

Silva (2002), levando em consideração a dimensão sócio-histórica dos gêneros textuais e ações discursivas dos sujeitos, afirma o seguinte sobre a "carta aberta":

De modo geral, esse gênero tem como finalidade discursiva publicizar algo seja para difamar ou para promover, por exemplo, uma pessoa pública, o serviço ou proposta política de uma empresa, de um órgão estatal ou não (SILVA, 2012, p. 73).

Assim, mesmo sendo primordialmente uma propaganda político-eleitoral que foi produzida e publicada dentro de certas condições sócio-históricas singulares, o texto em análise foi moldado em outro gênero que serve à mesma finalidade. A “carta aberta", ao mesmo tempo em que promove uma pessoa pública, um candidato a um cargo eletivo, também trabalha na persuasão dos possíveis (e)leitores de Flávio Dino, como é esperado de uma propaganda.

"A carta aberta dirige-se, com efeito, a dois destinatários ao mesmo tempo, sendo um deles o destinatário atestado e o outro o público dos leitores da publicação”. (MAINGUENEAU, 2008, p. 122). Assim como a carta de Flávio Dino dirige-se aos personagens no vídeo, dirige-se também aos telespectadores de sua campanha aos internautas e toda a opinião pública que forma os seus possíveis eleitores. Tal como na Carta a todos os franceses, de François Mitterand, analisada por Maingueneau (2008, p.125), a Carta aos maranhenses também leva o leitor a cair "numa espécie de armadilha, pois é levado a receber esse texto como uma correspondência privada, não como propaganda eleitoral".

Além da característica de ter sido produzidos por um grupo político, que ocupa, portanto, o lugar do sujeito remetente, colocando a população maranhense na posição de destinatário, podemos notar ainda a apresentação de uma situação problema na sequência discursiva: "Vejo uma terra tão linda e tão rica. Mas vejo também que essa riqueza chega para poucos". É preciso dizer ainda que a sequência "Vejo uma terra tão linda" é acompanhada no vídeo por imagens de uma das "riquezas" naturais que é hoje um dos pontos turísticos mais famosos do estado, os Lençóis Maranhenses (Fig. 6). 
Figura 5: "Vejo uma terra tão linda"

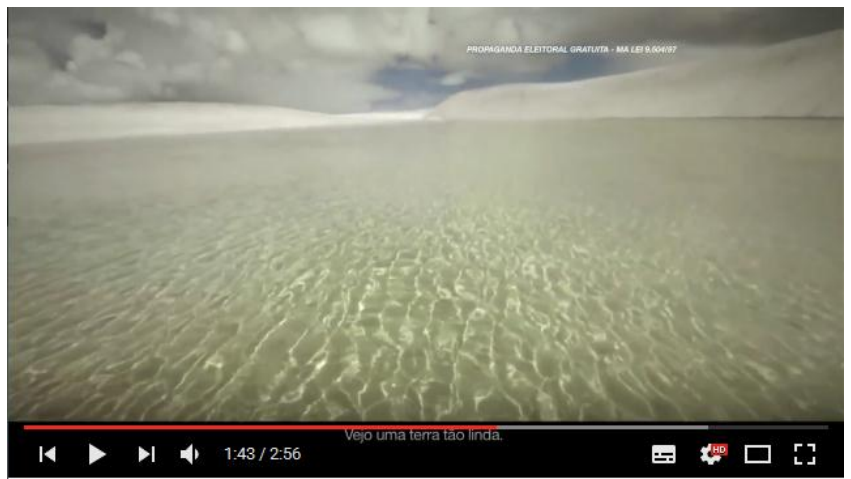

Fonte: : Youtube. Disponível em:

<https://www.youtube.com/watch?v=PMP0KomOIhU\&list $=$ =PLKWUfqq8cFHn8m6hWc0WYty7B_G_wuxjc >. Acesso em: $15 / 08 / 2015$.

Vislumbramos neste mesmo trecho, em seu conjunto com as imagens acima, uma interlocução com outra carta à qual a de Flávio Dino se liga, por meio de um domínio de memória: a famosa Carta do Achamento do Brasil, de Pero Vaz de Caminha.

Assim como na carta de Caminha fala-se de uma terra quase utópica, em tons de ufanismo e deslumbramento na descrição do local de seus recursos, que teriam a promoção do bem do homem como utilidade sagrada (PACHECO, 2004), na carta assinada por Flávio Dino, essas características também são observáveis. E não só na sequência discursiva citada, mas também em outras nas quais o remetente descreve seu objeto, tais como: "quero falar com vocês sobre a nossa terra", que é habitável; "O lugar em que queremos e podemos viver" e suas riquezas passíveis de exploração em prol do bem de todos; "Que as riquezas de nossa terra podem levar justiça e prosperidade para todos". Em "Somos um povo trabalhador, somos fortes, temos coragem e muita fé em Deus. Tenho fé que a hora chegou", percebemos uma referência à fé e a Deus, o que é um ponto importante, e já abordado por Courtine (2011) ${ }^{1}$.

Esse mesmo "problema" apresentado na carta também retoma outro discurso anterior, mas que emergiu na campanha do mesmo candidato, posicionado como um sujeito diferente do de 2014. Estamos falando do sujeito enunciador da campanha de Flávio Dino nas eleições de 2010 que, como dito no tópico 2, foi o ano em que o candidato perdeu o pleito ao mesmo cargo, quando contava com um número menor de aliados políticos em sua antiga coligação, a Muda Maranhão (PPS / PSB / PC DO B).

\footnotetext{
${ }^{1}$ Por limitação de espaço, não discutiremos esse aspecto da carta em análise.
} 
Figura 6: Campanha Flávio Dino 2010.

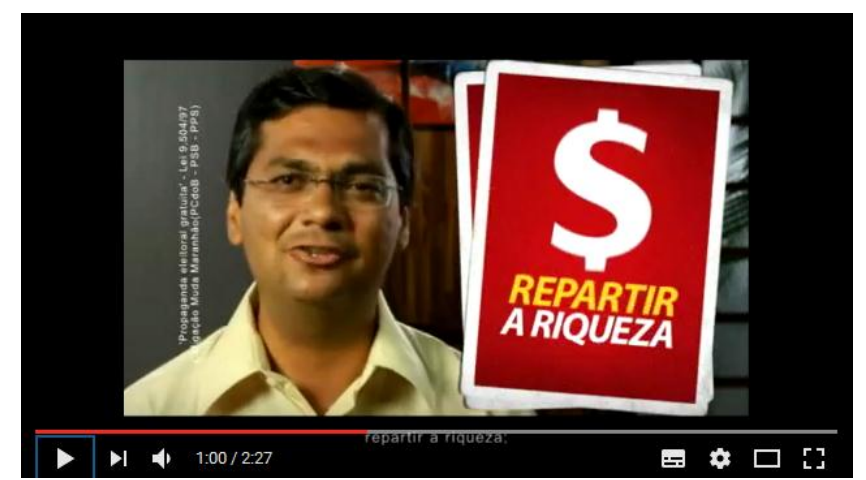

Fonte: Youtube. Disponível em: < https://www.youtube.com/watch?v=kBJo_3RJVf4>. Acesso em: $15 / 08 / 2015$.

Em 2010, em um dos vídeos da campanha eleitoral, que data de 17 de setembro, o sujeito enunciador é outro, e assim o seu discurso parte de outro lugar, enunciando o "repartir a riqueza" como uma das propostas do plano de governo (Fig. 7).

Esse mesmo discurso faz-se presente na campanha de 2014, como podemos notar na sequência: "Vejo uma terra tão linda e tão rica. Mas vejo também que essa riqueza chega para poucos". O personagem que lê o trecho "[...] e tão rica", não aparece em um grupo, ele é um dos poucos personagens que destoa dos outros de aparência mais humilde. É um senhor de cabelos grisalhos, branco, (Fig. 8) que observa um dia de trabalho em uma grande propriedade de produção agrícola, enquanto lê a Carta aos maranhenses. Essa diferenciação visual entre os personagens desse vídeo é a parte não-verbal que vai ajudar a construir esse sentido de que existe uma desigualdade social que deve ser solucionada. 
Figura 7: "Fazendeiro" - Uma carta pela Mudança do Maranhão.

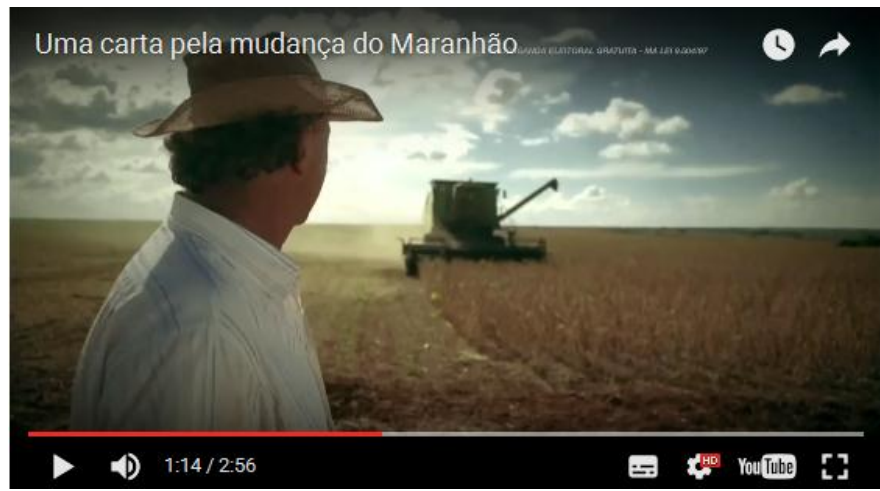

Fonte: Youtube. Disponível em:

$<$ https://www.youtube.com/watch?v=PMP0KomOIhU\&list=PLKWU fqq8cFHn8m6hWc0WYty7B_G_wuxjc>. Acesso em: 15/08/2015.

Essa retomada de um discurso anterior não acontece por uma citação direta, mas sutilmente através de uma "observação" do enunciador. Há a exaltação à beleza e riqueza da terra e logo em seguida um lamento na oração adversativa seguinte que também parece funcionar como uma denúncia sobre um problema social de desigualdade referente à distribuição de renda no estado. $\mathrm{O}$ enunciado liga-se a outro da mesma carta, "Eu acredito no Maranhão. Que as riquezas de nossa terra podem levar justiça e prosperidade para todos", no qual percebemos uma das propostas de solução para o problema apresentado: explorar as riquezas da terra de modo a obter um resultado coletivo igualitário.

Já no enunciado de 2010 há uma proposição direta e assertiva de "repartir a riqueza". Se existiu pesquisa e observação como as citadas pelo enunciador na carta de 2014 ("Tenho cruzado nosso estado de ponta a ponta"; "vejo também que essa riqueza chega para poucos"), ela não foi sinalizada no vídeo da campanha de 2010, o (e)leitor pode apenas supor pelo próprio enunciado, pois, se há a necessidade de "repartir a riqueza" ${ }^{2}$, é porque o enunciador supõe que esta riqueza está concentrada nas mãos de poucos. Uma das fontes a que nos remete essa ideia de divisão igualitária de riquezas é o Manifesto do Partido Comunista, obra clássica de referencial sobre comunismo, na

\footnotetext{
${ }^{2}$ Em relação ao enunciado "essa riqueza chega para poucos": a) consideramos que não é suficiente remeter ao Manifesto do Partido Comunista na análise do trecho; b) as diversas mudanças sociais e políticas pelas quais o mundo vem passando operam certamente transformações na forma como os partidos entendem a divisão de riquezas hoje; c) nem todos os partidos que falam de desigualdade social são comunistas.
} 
qual Marx e Engels (1848 [1998]) afirmam o acúmulo da riqueza em "mãos privadas" como condição essencial para a constituição e para a força de dominação da burguesia.

Percebemos também na sequência seguinte a argumentação do enunciador: "Por onde ando, percebo o mesmo desejo em cada olhar: o desejo de mudança. Quero conversar com você sobre o Maranhão do futuro. O lugar em que queremos e podemos viver". Essa argumentação apresenta primeiramente uma motivação para que exista a mudança proposta pelo enunciador: o desejo dos cidadãos maranhenses.

Segundo Foucault (1992, p.150), “a carta é simultaneamente um olhar que se volve para o destinatário (por meio da missiva que recebe, ele se sente olhado) e uma maneira de o remetente se oferecer ao seu olhar pelo que de si mesmo lhe diz.". Nesse olhar, o enunciador faz uma leitura de seu enunciatário e através dela vai construindo suas identidades e seus desejos. A solução para que haja essa mudança parece estar nos enunciados: "Juntos, a gente vai conseguir um Maranhão de todos. Vamos juntos pela mudança. Todos juntos pelo Maranhão". A repetição do adjetivo masculino "todo" e do adjetivo "junto" em suas formas do plural, assim como o uso recorrente da $1^{\text {a }}$ pessoa do plural sugerem a "união" como solução. Mas como aconteceria esta união? Bastaria os cidadãos maranhenses tomarem consciência do problema apresentado, desejar a mudança e se unirem para o solucionarem do modo que melhor entenderem?

Não. A solução é ao mesmo tempo uma condição, pois a dimensão discursiva desses enunciados e o gênero no qual se apresentam apontam ao seu enunciatário que o desejo de mudar a realidade social do estado e de continuar vivendo neste espaço rico e próspero, tal como apresentado pelo enunciador, acontecerá desde que haja o apoio do (e)leitor maranhense ao candidato, apoio este que deveria materializar-se em votos na eleição para governador do estado, no ano de 2014.

\section{Considerações Finais}

Em análises realizadas anteriormente, pudemos verificar que a associação do candidato Flávio Dino ao comunismo durante a campanha eleitoral de 2014 não aconteceu ao acaso. Pensamos que a discursivização do candidato como comunista se faz a partir de uma diversidade de outros discursos, em diferentes textos, em distintos momentos da história. A filiação partidária de Flávio Dino se tornou midiaticamente mais produtiva nas eleições estaduais no Maranhão de 2014 também em razão de sua 
candidatura nas urnas ter sido apresentada na mídia como estatisticamente mais forte que na eleição anterior. Mas a construção desse discurso se forma antes, em outro lugar, quando outros discursos sobre o comunismo, sobre capitalismo e sobre democracia se fizeram presentes em nossa história.

No caminho delineado nestas análises, vislumbramos também como os consensos e conflitos sobre "ser comunista" estão tão presentes e funcionam, a partir de um domínio de memória, na (re)produção de discursos identitários de políticos na pósmodernidade.

Os efeitos de sentido produzidos pela mídia sobre as identidades de Flávio Dino encontram sua regularidade na construção de uma oposição entre as identidades de comunista e cristão, sendo então a identidade "comunista" um tema não tranquilo, de conflitos. E a memória de um comunismo que se identifica primordialmente com a experiência histórica do poder soviético é retomada e funciona como um mecanismo da produção do efeito de contradição nas práticas discursivas sobre o candidato.

Já na análise apresentada neste artigo, a memória do comunismo na propaganda eleitoral gratuita do candidato não surge para produzir consenso entre os cidadãos maranhenses que, na leitura do sujeito enunciador, buscam a libertação de injustiças

sociais. É a construção de uma sociedade igualitária com bens e riquezas acessíveis a todos que é rememorada na campanha de Flávio Dino em 2014. É uma memória que já estava lá também no discurso político do candidato em 2010, mas que agora se materializa em uma apresentação de um problema construída entre a sutileza da conversação cotidiana estabelecida através das "cartas pessoais" e a sedução do vídeo e promoção que uma "carta aberta" proporcionam, apresentando Flávio Dino como um aliado do povo nesse processo de transformação da realidade maranhense.

\section{REFERÊNCIAS}

BAUMAN, Z. Identidade. Entrevista a Benedetto Vecchi. Rio de Janeiro: Jorge Zahar Editor, 2005.

BORGES, Arleth Santos. São luís: eleições 2008 na capital maranhense. Peças novas para um velho jogo. 2008. Disponível em: < http://www.fundaj.gov.br/index.php?option=com_content $\&$ view $=$ article $\& i d=2355 \% 3 \mathrm{~A}$ sao-luis-eleicoes-2008-na-capital-maranhense-pecas-novas-para-um-velho-jogo\&catid=58\&Itemid=414>. Acesso em: 10 agosto 2015 . 
COURTINE, J.J. As metamorfoses do homo politicus. In: PIOVEZANI, Carlos. SARGENTINI, Vanice. (Org.). Legados de Michel Pêcheux: inéditos em Análise do discurso. São Paulo: Contexto, 2011.

Análise do discurso político: o discurso comunista endereçado aos cristãos. São Carlos, SP: EDUFSCar, 2014.

DINO, Flávio. Flávio Dino Governador - Programa 14. Youtube. Disponível em: < https://www.youtube.com/watch?v=kBJo_3RJVf4>. Acesso em: 15/08/2015.

Uma carta pela mudança do Maranhão. Youtube, 2014. Disponível em: < https://www.youtube.com/watch?v=FOiwpAMgNRg>. Acesso em: 15/08/2015.

Carta aos Maranheneses. Youtube, 2014. Disponível em: $<$ https://www.youtube.com/watch?v=PMP0KomOIhU\&list=PLKWUfqq8cFHn8m6hW c0WYty7B_G_wuxjc>. Acesso em: 15/08/2015.

FOUCAULT, M. A arqueologia do saber. Trad. Luis Felipe Baeta Neves. 7a. ed. Rio de Janeiro: Forense-Universitária, 2008.

A ordem do Discurso. São Paulo: Edições Loyola, 2010.

A escrita de si. In: FOUCAULT, Michel. O que é um autor? Lisboa: Passagens. 1992.

GREGOLIN, Maria do Rosário V. A tipologia textual e a construção da referencialidade no discurso jornalístico. Trabalho apresentado no $16^{\circ}$ Congres International des Linguistes, Paris, 1997.

Análise do discurso e mídia: a (re)produção de identidades. Comunicação, mídia e consumo. São Paulo v.4. n.11 p.11-2 5, 2007.

Identidade: objeto ainda não identificado? Disponível em: $<$ http://www.estudosdalinguagem.org/seer/index.php/estudosdalinguagem/article/view/ $88>.2008$.

HALL, S. A identidade cultural na pós-modernidade. Rio de Janeiro: DP\&A, 2006.

MAINGUENEAU, Dominique. Cenografia epistolar e debate público. In: MAINGUENEAU, Dominique. Cenas da Enunciação. Trad. Sírio Possenti e Maria Cecília Pérez de Souza e Silva. São Paulo: Parábola Editorial, 2008.

MARX, K.; ENGELS, F. Manifesto do Partido Comunista. 9. ed. Petrópolis, RJ: Vozes, 1998.

MOURA, MARIVÂNIA DE MELO. Cultura política, voto e eleição em São luís do Maranhão: uma análise do pleito de 2010. 120 p. Dissertação (Mestrado em História Social) - Universidade Federal do Maranhão - UFMA, 2013.

PACHECO, Isabel Maria de Jesus. $O$ imaginário da carta de Caminha e sua apropriação pelo turismo. 151 p. Dissertação (Mestrado em Cultura e Turismo) - 
Universidade Estadual de Santa Cruz - UESC e Universidade Federal da Bahia UFBA, 2004.

PÊCHEUX, Michel. Papel da memória. In: ACHARD, P. et. al. Papel da memória. Campinas: Pontes, 1999, p. 49-57.

PORTAL VERMELHO. Carta aos Maranhenses, por Flávio Dino. 2014. Disponível em: <http://www.vermelho.org.br/noticia/248217-1> . Acesso em: 15/08/2015.

SILVA, Jane Quintiliano Guimarães. Um estudo sobre o gênero carta pessoal: das práticas comunicativas aos indícios de interatividade na escrita dos textos. 209 p. Tese (Doutorado em Estudos Linguísticos). Faculdade de Letras. Universidade Federal de Minas Gerais - UFMG, 2002.

TRUFFI, Renan. "Se o senhor for eleito, vai implantar o comunismo no Maranhão?". Carta Capital, 25 ago. 2014. Disponível em: $<$ http://www.cartacapital.com.br/blogs/carta-nas-eleicoes/se-o-senhor-for-eleito-vaiimplantar-o-comunismo-no-maranhao-5998.html>. Acesso em: 12 julho 2015. 